\title{
Dora Ferreira da Silva e Carlos Drummond de Andrade: \\ a sagração da poesia e da amizade na "Trilogia da mangueira"
}

Enivalda Nunes Freitas e Souza Universidade Federal de Uberlândia

Resumo: $O$ objetivo deste artigo é a análise dos poemas que compõem a "Trilogia da mangueira", composição que a poeta paulista Dora Ferreira da Silva ofertou ao amigo e correspondente Carlos Drummond de Andrade. A amizade se estendeu por quase vinte anos, ainda que jamais tenham se encontrado. Conversas ao telefone, cartas e poemas alimentavam o afeto mútuo. Para homenagear o poeta amigo, Dora transforma a mangueira da "Infância" de Drummond na mitica árvore de raizes para o ar, fazendo-a ser escalada por um Menino sagrado, eternizando, desta forma, o Menino Drummond e sua poesia.

Palavras-chave: Dora Ferreira da Silva, Carlos Drummond de Andrade, Poesia. 
Dora Ferreira da Silva é uma das poetas mais singulares que a literatura brasileira já produziu. Foi poeta, ensaísta, tradutora e divulgadora cultural. Sua poesia emana da imersão no universo religioso, de onde extrai de mitos cristãos e pagãos - sobretudo os gregos - a riqueza estética e a fina percepção da temporalidade humana. Há que se considerar, também, o aproveitamento de uma matéria cósmica sacral que começa no jardim de sua casa, passa pelas ruas de São Paulo e se estende às montanhas do Itatiaia. De igual forma, a memória, o conhecimento - como tradutora e leitora - de poetas místicos e dos principais poetas do século XX, os estudos de psicologia e de religião, o enamoramento com a música, a dança e a pintura contribuem para a constituição de uma poesia rigorosa e essencial, assentada na origem mítica da linguagem poética, quando esta ensaia a hierofania do mundo a cada realização.

Dora Ferreira da Silva nasceu em Conchas/SP, em 01/07/1918, e faleceu em São Paulo, em 06/04/2006. Dentre suas atividades culturais, destaque para a criação, com o marido, o filósofo Vicente Ferreira da Silva, e o amigo Milton Vargas, da revista Diálogo (1955-1963), em que saíram várias traduções suas, além de ensaios. A revista era respeitada e reconhecida pelos intelectuais brasileiros como um dos principais veículos de cultura que circulavam naqueles anos. Após o falecimento precoce do esposo, cria, com a colaboração de Vilém Flusser e Anatol Rosenfeld, a revista Cavalo Azul (1964), voltada para artes e literatura. A Cavalo Azul alcançou doze edições, e foi na número 1 que Guimarães Rosa publicou, pela primeira vez, "As garças".

Ainda que longe dos círculos literários - a não ser o de sua própria casa, na Rua José Clemente, em São Paulo - a poeta obteve, em vida, reconhecimento pelo seu trabalho. Já pela primeira publicação, Andanças (1970), recebe o Prêmio Jabuti; em 1982 foi a vez de Talhamar ser contemplado com o Prêmio Pen Clube de São Paulo; com Poemas da estrangeira, de 1996, o Prêmio Jabuti volta-lhe às mãos; sua Poesia reunida, de 1999, alcança o Prêmio Machado de Assis, da Academia Brasileira de Letras. A poeta recebeu seu último Jabuti em 2004, por Hídrias. Atualmente, o Instituto Moreira Salles é guardião de seu espólio literário.

A poiesis de Dora Ferreira da Silva é permeada pela noção do sagrado. As traduções de Rainer Maria Rilke, Jung, Hölderlin, S.-J. Perse, T. S. Eliot, O. V. de L. Milosz, W. B. Yeats, D. H. Lawrence, as traduções dos poetas místicos, a leitura de Mircea Eliade, atividades exercidas concomitantemente ao seu ofício de poeta, podem ter contribuído para que a poeta firmasse, ao longo 
de sua carreira, o gosto pela reflexão sobre a "essencialidade desconhecida", sobre o mistério que se avizinha da arte e dos homens. Seguindo esse mesmo mistério que subjaz às forças arquetípicas da linguagem, sua poesia revigora os mitos, reencena-os à luz da contemporaneidade e se coloca a serviço da celebração da vida e da harmonia cósmica, sem perder de vista a conjunção da luz com as trevas, fonte do equilíbrio para uma discípula e tradutora junguiana.

Esse mesmo equilibrio é a medida de sua arte de versos livres ao tempo em que é musical e exata. Ivan Junqueira observa uma perfeita fusão de fundo e forma promovendo a "tessitura inconsútil" de seus versos: "nenhum poder humano poderá remover a tessitura inconsútil da poesia de Dora Ferreira da Silva, tamanha é a fusão entre forma e fundo, furtando-se assim a qualquer decodificação que tente eviscerá-la como se fosse um organismo morto”. '

\section{Dora e Drummond: uma amizade escrita}

"Encanto-de-gente", "Minha boa amiga", "amiga querida", "muito querida”, é assim que o poeta Carlos Drummond de Andrade dirige-se a Dora Ferreira da Silva em cartões de natal, cartões de aniversário, cartas com felicitações pelos livros lançados e cartas de reconhecimento à qualidade dos versos. Ao relembrar os primeiros críticos de sua obra, como Ernesto Grassi, Enzo Pacce e Euryalo Cannabrava, a poeta fala do carinho e do interesse de Drummond por sua obra registrados em cartas ou expressos por telefone:

Carlos Drummond de Andrade também foi um leitor muito fiel. Nunca o conheci pessoalmente. Falávamos por telefone ou por cartas. Tenho cartas dele sobre todos os livros que lhe mandei. Em Poemas da Estrangeira publiquei o poema que dedicou a mim. Liguei para perguntar se poderia usar. Disse-me: "Nunca estarei tão bem como quando perto de você". Foi sempre muito generoso e estimulante. ${ }^{2}$

Como se pode comprovar no Instituto Moreira Salles, Carlos Drummond de Andrade manteve correspondência com a amiga Dora Ferreira da Silva entre 1971 (a primeira publicação da poeta é de 1970, Andanças)

1 JUNQUEIRA. Pensamento e emoção. In: SILVA. Cartografia do imaginário, p. VIII, IX.

2 GALVÃO. Entrevista de Dora Ferreira da Silva. In: Jornal de Poesia. 
e 1987. Vinte dias antes de sua morte, e oito antes da morte da filha Julieta, Drummond ainda lhe escreveria, falando de seu "duro momento". Sempre atento à produção da amiga, Drummond elogia-lhe as traduções, como a do poeta místico São João da Cruz, "de uma tão refinada música espiritual, que você soube passar para o português com pureza e mestria". Sobre o primeiro livro de Dora, Andanças (1970), salienta a presença de "uma voz tão pessoal", além da celebrada habilidade da poeta no trato com as imagens, como suas criações de "Raízes que falam... e cristais que cintilam na sombra". Drummond escreve, ainda, que a poesia de Dora é a revelação do "outro", e é peremptório quanto à sua capacidade de manejar o verbo poético: "Você alcançou aquela altura em que pensamentos e emoção se aliam na mais veludosa expressão verbal". Drummond registra que em qualquer poema se encontra o "sentido profundo das coisas”, e assinala o sentido musical que acompanhará a poeta ao longo de sua produção, tanto que uma de suas obras é intitulada Poemas em fuga, e uma das três póstumas homenageia Beethoven: Appassionata. Drummond escreve: "Suas Andanças estão aqui, andantes, dançantes, libertando em música as 'formas prisioneiras', numa contínua criação de poesia." Em uma das cartas, Drummond fala de um poema que Dora lhe enviara, o "Poema em rosa", "em instante de comunicação afetiva", com o seguinte comentário: "Você criou uma atmosfera de sonho no jardim e no tempo, em que tudo fica pairando em forma de palavras... toda a admiração agradecida". Sobre Jardins (esconderijos), pontua que uma "grave e quase silenciosa poesia" o toca, e qualifica a poesia da amiga de "inefável", explicando que sua palavra transcende "a comum objetividade que elas oferecem". Não finaliza sem dizer que a poesia da amiga faz bem a ele. Em carta de 1980, Drummond escreve sobre um "belíssimo poema que, ausente", não mereceu e ganhou, esclarecendo que a notícia de sua ida a São Paulo foi dada à sua revelia, um "poeta-bicho-do-mato". Diz, ainda, à amiga, que espera o Talhamar com "aflição de menino esperando uma coisa gostosa". Drummond volta a falar do poema que Dora lhe fizera quando teve frustrada a expectativa de conhecer o célebre e querido amigo. O poema é intitulado "Ele não estava”, e será publicado dez anos depois, em Poemas da estrangeira. O amigo escreve que "sentiu" não ter estado para receber a rosa que a poeta the ofertaria. No referido poema, Dora descreve o ritual de embelezamento a que se entregou para encontrar o amigo.

Sobre o carinho da amiga, geralmente traduzido em poesia, Drummond haveria de dizer que seus versos lhe deram "força" e "emoção" e o acompanharam em momentos "atrapalhados". 
O assunto da correspondência não se limita a livros e poesias. Com fervor, Drummond cumprimenta-a pelo aniversário, chamando-a de "criatura deliciosa de sabedoria e graça", como em 1ํ de julho de 1985, e envia "beijo-alegria" e "beijo-saudade", um ano depois. Nos momentos agônicos que antecedem a morte de Maria Julieta Drummond de Andrade, Dora envia de Itatiaia poemas ao amigo, assim respondidos: "Seu recado do alto da montanha, com as flores de mel, clareou meu duro momento por que estou passando".3

As cartas de Carlos Drummond de Andrade a Dora Ferreira da Silva testemunham o franco interesse, a ternura e o zelo do poeta mineiro, sempre dado a delicadezas e afabilidades com seus eleitos. Com Dora, Drummond cultivava a amizade, vivendo as reverberações da poesia - a sua essencialidade - sem se impor a exigência acadêmica de emitir longos e ponderados juízos de valor, ainda que jamais lhe escapasse a grandeza da poesia da amiga, tantas vezes registrada.

O número 10 da Cavalo Azul, publicado na primavera de 1988, traz uma série de três poemas dedicados a Carlos Drummond de Andrade, sob o título de "Trilogia da mangueira". A trilogia revela mais do que o carinho mútuo entre os dois poetas amigos. É uma revelação da poética sacral de Dora Ferreira da Silva, bem como uma oportunidade para rever o espírito da arte drummondiana, que não deixou infenso nenhum de seus leitores.

\section{Drummond por Dora: o Menino sagrado}

"Trilogia da mangueira"

Dora Ferreira da Silva

a Carlos Drummond de Andrade

I

O Menino sobe os galhos da mangueira pisa o cheiro das folhas o escuro setas de sol se infiltram em verdes cintilações

3 A correspondência passiva de Dora Ferreira da Silva com Carlos Drummond de Andrade pode ser conferida no Instituto Moreira Salles - RJ. 
O Menino se fere no lenho de escamas grossas

(chupa o sangue do dedo)

devagar

vai subindo

leva corpo

alegria

(...)

No alto um pássaro canta:

- Aqui a mangueira principia

raízes no céu

bebendo em taça transparente

orvalho de um Jardim de amores

raízes

de finos cabelos

enovelados

dourados de sol

Lá em baixo

filhinho amado

$$
\begin{aligned}
& \text { a copa } \\
& \text { é cornucópia } \\
& \text { de flores }
\end{aligned}
$$

$$
\text { e frutos }
$$

derramados

O Menino está no meio

e ouve o pássaro

cantando:

Prepara teu coração

suas pedrinhas seus escuros

seu obscuro chão

usa a palha bem seca

o capim cheiroso

Chama o boi num aboio

puxa o burro teimoso

e as ovelhas virão

sem que as chames:

guiarão os pastores

O presépio lá está

vazio à espera

em qualquer estação 
Mas prepara

teu coração

que os anjos vêm apressados...

Do alto a luz se infiltra

nas fendas ignoradas

do teu peito profundo

Não te assustes:

é um Deus-Menino

que só quer te despertar

O Menino está sem medo

Subir mangueira até a raiz

é uma aliança

entre o céu

e o chão-criança $^{4}$

$\mathrm{Na}$ particularidade de uma imagem - a mangueira - a poeta homenageia o amigo, evocando seu universo poético e simbólico, trazendo para o tempo presente, para a memória do leitor, aquela mangueira escalada pelo menino de "Infância": "Eu sozinho menino entre mangueiras". Revigora, assim, a antiga imagem em símbolo universal de ascensão, mais fortalecido pela presença do Menino. Árvore e Menino - o amigo Drummond - são colocados em escalada para o alto, lá onde se encontram a luminosidade e a essência das coisas. Mas a árvore é, sobretudo, o ideal de ressurreição, haja vista a grande quantidade de mitos em que os mortos se metamorfoseiam em árvores e plantas. Durand lembra que Bachelard, o fenomenólogo das imagens, "entreteve-se a mostrar nos poetas modernos essa fantasia do prolongamento vegetal e profético da vida". Da árvore emana toda uma vontade de também trocar a casca velha por uma nova, de reverdecer com vigor e frescor. No cimo da árvore está a soberania, e é para lá que o Menino caminha. Verticalidade, ascensão, elevação espiritual. A elevação (essencialmente angélica) e a purificação são isomórficas. Portanto, mediando a conexão entre céu e terra, a imaginação completa da árvore é ascensional, e o Menino que a escala é o que se projeta no tempo eternamente criança. É assim que Dora Ferreira da Silva percebe o amigo Drummond.

4 SILVA. Cavalo Azul, n. 10, p. 76.

5 DURAND. As estruturas antropológicas do imaginário, p. 298. 
A mangueira da infância é a árvore da vida. A árvore relaciona-se às idades, pela sua existência sazonal e cíclica. Segundo Eliade, é a sacralidade que desvenda as estruturas mais profundas do mundo. O cosmos só se apresenta como uma "cifra" segundo uma perspectiva religiosa. Para o pensador, "a árvore conseguiu exprimir tudo o que o homem religioso considera real e sagrado por excelência". ${ }^{6}$ Mas toda experiência inicial - subir numa árvore - é um exercício de sacrifício: o sangue é a prova do rito de passagem, "O Menino se fere no lenho de escamas grossas / (chupa o sangue do dedo)", sugerindo que a ascensão é precedida por uma queda. Para o rito ascensional do Menino, a poeta lança mão, ainda, das imagens do pássaro e do jardim. Desta forma, as imagens Pássaro / Árvore / Menino / Jardim formam uma constelação simbólica do crescimento, da sublimação, da divinização. Com essas imagens, repete-se na terra a perfeição do macrocosmo celeste, e Drummond converte-se no Menino sagrado.

A poeta é capaz de dar concretude às sensações mais abstratizantes e fugidias à linguagem, como o cheiro, o raio de sol. A essas imagens se contrapõem (se fundem) os pés, o lenho, o corpo, o sangue, como em "pisa o cheiro das folhas". De igual modo, o movimento de subida e descida (ascensão do humano e descensão do divino) se mostra pelo corpo que sobe e pelos raios de sol que descem. Os raios descendo, fecundantes como setas (trazendo iluminação e graça), promovem a hierogamia - o casamento sagrado - entre céu e terra, consórcio necessário à sacralização do mundo, uma vez que só o céu é divino. O canto do pássaro é a palavra da mãe celeste, o pássaro do Espírito Santo, a vontade de transcendência.

A poeta converte a mangueira na célebre árvore invertida, a que mergulha suas raízes no céu. Se a árvore é o devir para o homem, as raízes para o ar completam a totalidade cósmica. As raízes para o céu indicam que é preciso penetrar nas forças vitais divinas, que dão frutos aos mortais. Esta árvore mítica que mergulha suas raízes no empíreo e cobre com seus galhos a terra inteira é conhecida pela Cabala, por Dante, por povos nórdicos. No Bhagavad-Gita, a árvore invertida é a Ashvattha: "Ashvattha, a eterna árvore simbólica, tem suas raízes, a fonte primeva, firmadas nas alturas, no Ser Supremo, e seus ramos se desdobram para baixo, pelo mundo criado, em incessante mutação - quem isso compreende conhece o Universo" ${ }^{7}$ Jacques Brosse, francês estudioso da

6 ELIADE. O sagrado e o profano, p. 124. Grifo do autor.

7 KRISHNA. Bhagavad gita, p. 122. 
mitologia das árvores, completa: "Par voie de consequénce, c'est à Açvatta que doit s'attaquer l'ascète, le renonçant, s'il veut transcender la condition d'homme incarné, se retirer définitivement du cycle des naissances et des morts dont il se considère le prisonnier."

A raiz suga a seiva na Origem, o Jardim suspenso, que é o Paraíso. A árvore (o corpo humano) é a taça / receptáculo do alimento sagrado. As raízes direcionadas ao empíreo buscam nossa alma imortal que está no céu, ao mesmo tempo que dá lição de desapego. Os ramos que se lançam à terra são uma manifestação do sagrado no cosmo, uma franca demonstração de que o homem descende do divino, o que leva a imaginar a árvore invertida como imagem de reversibilidade entre divino e humano: "esta árvore invertida insólita, que choca nosso sentido da verticalidade ascendente, é bem signo da coexistência, no arquétipo da árvore, do esquema da reciprocidade cíclica, da reversibilidade do inferior e do superior". ' Bachelard postula que a raiz corresponde a um arquétipo sepultado no inconsciente e suas metáforas são sempre simples e compreendidas. De todo modo, ela é um eixo da profundidade: sobe ao ar e desce à terra, comunica-se com os deuses e com os mortos. A raiz é, em síntese, a imagem psíquica do "morto-vivo", uma vez que, mesmo depois de cortada uma árvore, há esperança de ela reverdecer.

Confirmando a premissa de que árvore e homem são isomórficos isomorfismo assim definido por Durand: "Pela sua verticalidade, a árvore cósmica humaniza-se e torna-se símbolo do microcosmo vertical que é o homem" ${ }^{11}$-, as raízes da mangueira se antropomorfizam - raízes de finos cabelos -, revelando a manifestação concreta da vida cósmica, quando homem, natureza e deus são indistintos.

Na mangueira da eterna Infância de Drummond estão as flores e os frutos abundantes (cornucópia) que foram procurados no mundo espiritual. A cornucópia, palavra inusual nesses tempos de experiências dessacralizadas, é símbolo da abundância e da fertilidade nos ritos pagãos, e recua ainda mais o leitor de Dora Ferreira da Silva para o tempo arquetípico, não só para o tempo do Menino que se encena no texto, mas para a origem mítica da linguagem poética. O "filhinho amado", que se encontra no meio do caminho, pode buscar

8 BROSSE. Mythologie des arbres, p. 78.

9 DURAND. As estruturas antropológicas do imaginário, p. 344.

10 BACHELARD. A terra e os devaneios do repouso, p. 223-224.

11 DURAND. As estruturas antropológicas do imaginário, p. 342. 
na Origem (a infância) o alimento das primícias sagradas. Como afirma Durand, "toda árvore que brota ou floresce é uma árvore de Jessé". 12 A cornucópia é, assim, a promessa do eterno retorno que se cumpre.

No sagrado de Dora Ferreira da Silva, os deuses pagãos convivem harmoniosamente com as divindades cristãs. Assim é que nos versos que se derramam sobre a página, numa insinuação icônica dos galhos pendentes sobre a terra, surge a anunciação do nascimento de Jesus pela evocação do presépio. Para o novo nascimento é preciso preparar o coração, transformá-lo num presépio composto por pedras, escuros, palha seca e todos os elementos que ora se fazem sagrados pela perda da dualidade. Se o coração se abre à participação mística, a luz se infiltra nas fendas ignoradas, e o homem é capaz de dominar sua natureza díspare e comunicar-se com os anjos, os primeiros mensageiros da luz divina, do Deus-Menino que habita o Menino. Por fim, "Subir mangueira até a raiz" é o esforço para reconquistar uma potência perdida, uma essência que foi degradada pela queda, como teoriza Durand a propósito dos símbolos ascensionais. ${ }^{13}$

\section{II}

mar de tules

Tambores percutem

tamborins desnudam delicadamente a lua

violinos transportam amantes

Ausenta-se o sono do mundo

e tudo parece terminado

a política lá estivera

numa alegoria de cavalos brancos

e bonecos

a Noite sorria com dentes de ouro

Os que olhavam da gaiola dos camarotes

moviam braços semi-atados

e também sorriam

Tudo parece terminado

12 DURAND. As estruturas antropológicas do imaginário, p. 339.

13 DURAND. As estruturas antropológicas do imaginário, p. 145. 
O que resta então para a Mangueira?

A aurora surge

$$
\begin{aligned}
& \text { pé ante pé } \\
& \text { nua e nacarada } \\
& \text { sem máscara }
\end{aligned}
$$

pousa uma luz branca

nos rostos quase sem maquilagem

As Crianças chegam à Escola

franzina

e delicadamente

porque depois da Noite vem o Dia

$$
\text { e a Mangueira }
$$

Que gente mais alegre e descansada!

O mundo acaba de ser criado

e esta gente com ele:

dançam sem pressa

sem asas

mas com muito de pássaro

Os risos são flores

na manhã natural

o ouro cintila

$$
\text { no engaste dos olhos }
$$

além da ourivesaria

Tudo vem do céu?

A terra em taça

acolhe uma água de luz

- o outro dia da noite que se foi

um puro vagido

um Dia nascido na Manjedoura

da rua

cadê a terra?

cadê o céu?

Os anjos são trans

Parentes

e mais belos:

irmãos diletos

falam um dialeto

um pouco diverso 
do que se ouve na rua

na boca das Crianças

que vão a pé

até o terceiro Milênio ${ }^{14}$

pelo universo

A segunda parte da trilogia traz a Mangueira despontando sobre a cidade, quando passa por uma Noite de objetos misturados - Drummond diria "Por entre objetos confusos / mal redimidos da noite", em seu "Morte do leiteiro" que custa passar, antes de conhecer a aurora. É possível divisar uma polis híbrida, tensa. Sob a névoa que cobre a cidade - "mar de tules" - a poeta desvela uma situação política desalentadora, quando a esperança do "cavalo branco" mal se insinua e já se dissolve em "bonecos". Para sugerir a tensão política da "noite geral" ", a poeta recorre à antropomorfização da noite e da cidade, convertendo estrelas, semáforos e luzes em "dentes de ouro", e fala de pessoas de "braços semi-atados" que olham da "gaiola dos camarotes" - talvez, das sacadas dos apartamentos. Mas não há desespero. Em meio à noite, "tambores", "tamborins" e "violinos" despertam a lua e os amantes. Mesmo devotando seus versos à atemporalidade humana, Dora Ferreira da Silva jamais negligenciou seu tempo histórico, tratando de questões como ecologia, violência, fome, descrença na linguagem, haja vista seu livro Uma via de ver as coisas, de 1973. Ao elaborar a "Trilogia da mangueira" em homenagem ao amigo do Sentimento do mundo e d'A rosa do povo, a poeta traz, a seu modo, a lira altissonante para despertar o mundo, quando "tudo parece terminado" nessa noite confusa de pessoas semi-impotentes.

Se no poema anterior Menino e Mangueira se fundem nos cimos, iluminados por raios celestes, nessa segunda parte pode-se crer que entra um terceiro elemento, a Poesia, e a Mangueira passa a ser tomada como metáfora da poesia, assim como a rosa já o fora nos versos do poeta amigo. "O que resta então para a Mangueira?” Resta à Poesia-Mangueira o gesto inaugural, fundante, capaz de revigorar o espírito humano e devolver-lhe a esperança, assim como leite e sangue se enlaçaram "formando um terceiro tom / a que chamamos aurora". ${ }^{17}$

14 SILVA, Cavalo Azul, n. 10, p. 78.

15 ANDRADE. Poesia e prosa, p. 133.

16 ANDRADE. Poesia e prosa, p. 132.

17 ANDRADE. Poesia e prosa, p. 133. 
Colada à terra, a poesia-mangueira se eleva para melhor observar o destino dos homens e recriar o mundo pelo poder da palavra. E eis que "a aurora surge", "porque depois da Noite vem o Dia / e a Mangueira". A Noite se dissolve e o mundo é recriado com graça e alegria. Agora não há mais "dentes" nos risos, mas "flores"; os braços "semi-atados" se desfazem e as pessoas bailam, com olhos iluminados.

Nos versos finais, a poeta retoma a poética sacral que define sua obra, convocando símbolos familiares como "céu", "terra", "anjos", transformando a consciência política da Noite em explosão de vida iluminada. O verso interrogativo "Tudo vem do céu?" evidencia que a transformação esperada só ocorre por forças transcendentes já manifestas nesse mundo, que fazem da prosaica rua a manjedoura: "um Dia nascido na Manjedoura / da rua". A terra é o receptáculo para as bênçãos divinas que se anunciam no dia cristalino, cuja claridade e leveza são forjadas na imagem "água de luz". Já não há distinção entre terra e céu, uma vez que o mundo se abre à participação mística, e a Poesia brota da rua. Assim como os anjos são parentes, a rua é sagrada, e as Crianças já não caminham à Escola, mas a um "terceiro Milênio" parente da eternidade.

\section{Nos telefonemas, um reino de palavras}

Quando não se comunicavam por carta, o telefone era chamado ao exercício da amizade, como se pode conferir no trecho seguinte de um bilhete, escrito por ocasião do aniversário da poeta: "Tentei telefonar-lhe ontem à noite, para ser o primeiro a comemorar a data, mas a Telerj deu-me um número que estava sempre sem comunicação, e que suponho fosse errado." ${ }^{18}$

\section{Telefonema}

Os fios telefônicos ficaram repletos de andorinhas que pousaram para ouvir o murmúrio do regato: um reino de palavras teria sido interceptado

$$
\text { pelos pássaros }
$$

se uma andorinha não bicasse à minha janela.

Uma voz suave

18 Dos arquivos da poeta no Instituto Moreira Salles - RJ. 
que conheço de cor

falou:

- Outrora as Crianças ficavam boquiabertas

diante das bocas-de-leão

que mostravam a língua nas velhas áleas.

Alguém de cotovelos fincados no parapeito da janela olhava distraidamente.

A casa derramava uma obscuridade limpa

(barulho de panelas

frituras,

não se sabe quem lidava com um chuveiro que nunca funcionava.)

Estirava-se o dia ao sol

com seus grãos de aflição.

(...)

- O mundo é tão grande

mas cabe nesta janela;

na cama há um mar em procela

(sei que vieste me beijar)

(...)

- “Assino-me no cálice

de estrias fraternais.

O pensamento cale-se.

É jardim,

nada mais."

(...)

- A meu lado um perfil do silêncio.

- Partir para o silêncio:

poema e poeira da viagem...

- Mas é o reino das palavras que nos cabe,

meu encanto-de-gente;

sempre o soubemos

e passamos a vida a limpo.

- Linha errada

Carlos.

A palavra mais bela

vive e morre na boca,

é o por dizer. 
- Não se exaspere

amiga.

O reino das palavras foi o começo

$$
\text { e dele me evadi }
$$

completo.

Agora posso vê-lo daqui

mais belo do que nunca

pirita faiscando

ao pé das cachoeiras

perto de Minas,

terra minha!

Brinquedo sem malícia

(você o inventou):

bêbados de imaginação

não precisamos ir nem vir;

emergimos de um lago

a qualquer momento.

E sem passar pelo vale

não é que sua voz aqui chegou?

Num telefonema-poema

Ou nas asas do puro Amor.

Em 22 de janeiro de 1982, Drummond escreve a Dora Ferreira da Silva a propósito de uma série de poemas que ela lhe enviou, ora intitulados "Telefonemas". É nessa carta que Drummond faz uma síntese da arte da amiga: "Você alcançou aquela altura em que pensamentos e emoção se aliam na mais veludosa expressão verbal". Mais tarde, essa apreciação crítica seria publicada na orelha de Talhamar (1982).

O poema que encerra a trilogia se inicia com o amigo Drummond personificado em andorinha, uma vez que sua voz não pode alcançar a poeta via telefone. Mensageiros da distância e do mundo invisível, portanto parentes dos anjos, os pássaros são imagens muito comuns e desgastadas na literatura, o que exige que o poeta recrie uma "espécie nova" a cada verso, garantindo o frescor da imagem. Assim é que a andorinha dos versos iniciais não é um sinal da presença do amigo, mas o próprio amigo que chega com sua voz doce e íntima a prosear sobre os tempos de antigamente, marcados pela simplicidade,

19 SILVA. Cavalo azul, n. 10, p. 79-82. 
mas que conheciam, também, os "grãos da aflição". A homenagem ao amigo funde imagens da casa da poeta - o barulho na cozinha, o chuveiro enguiçado - a evocações gerais ao tom memorialístico de Boitempo, do Fazendeiro do ar, bem como a outras obras do "reino de palavras" drummondiano, facilmente identificadas em versos seguintes.

O tom prosaico e memorialístico do início do canto cede, nesta última peça, a outros temas drummondianos, como o amor, o silêncio, as palavras, Minas. Os versos retomam o sentimento do mundo pelo viés dos amantes, recriando "O mundo é grande", de Amar se aprende amando: "O mundo é grande e cabe / nesta janela sobre o mar. / O mar é grande e cabe / na cama e no colchão de amar. / O amor é grande e cabe / no breve espaço de beijar." ${ }^{20}$ Em seguida, é a última estrofe de "Flor experiente" que é convocada para dar conta da ausência sentida do amigo: "Assino-me no cálice / de estrias fraternais. / O pensamento cale-se. / É jardim, nada mais."

É como um "perfil de silêncio" que a poeta percebe o amigo, trazendo na metonímia toda a poética drummondiana da busca das palavras e a decantada impotência do verbo poético para a expressão do sentimento, ainda que o silêncio seja a origem mesma do poema. Se se consideram as posturas de cada poeta frente à linguagem, a da poeta do sagrado e a do poeta mineiro, nesses versos há uma inversão de valores quanto à crença na força da palavra poética: a poeta Dora Ferreira da Silva, que jamais duvidou do alcance da palavra, coloca o poema no reino do silêncio, lembrando que a palavra mais bela é a que está por ser dita, mas Drummond insiste na intimidade da palavra com o homem, ainda que este passe ao largo delas, "a limpo": "Mas é o reino das palavras que nos cabe, / meu encanto-de-gente; / sempre o soubemos / e passamos a vida a limpo." De Drummond, sabe-se fartamente de sua luta com as palavras, sobretudo do exercício exaustivo para que estas não falassem demais, desmedida intolerável para um poeta dado ao silêncio. Em "O constante diálogo", o poeta mineiro versa sobre as várias formas de diálogo, que variam conforme os modos de existir, mas finaliza o poema elegendo o "melhor silêncio" como uma possibilidade factual para o diálogo: "Escolhe teu diálogo / e / tua melhor palavra / ou / teu melhor silêncio / Mesmo no silêncio e com o silêncio / dialogamos". 22 Para Dora Ferreira da Silva, a palavra poética é "aragem sagrada", "gesto criador", "palavra inicial" capaz de refazer o mundo: "A palavra - sopro

20 ANDRADE. Poesia e prosa, p. 1043.

21 ANDRADE. Poesia e prosa, p. 1003.

22 ANDRADE. Poesia e prosa, p. 851. 
cosmogônico - nossa arma de predileção, / nossa bomba amorosa de efeito retardado / mas seguro". ${ }^{23}$ Como os dois amigos que se amam e se entendem à distância, é à distância que se dá a reconciliação do poeta mineiro com o reino das palavras: "Agora posso vê-lo daqui / mais belo do que nunca". Surge, então, a imagem da "pirita", substantivo que a poeta converte em verbo para trabalhar com a ambiguidade do brilho que o metal/palavra encerra, uma vez que a pirita é conhecida como "ouro dos tolos". Com todo seu silêncio e porosidade, a palavra drummondiana continua piritando em sua Minas.

\section{Dora por Drummond: a "convergência extasiada"}

A comunicação afetiva entre os dois amigos que jamais se viram pessoalmente se dava pela poesia e pelo sentimento mútuo de integração aos elementos cósmicos, no silêncio das coisas. De tal modo integrados, os amigos não precisavam "ir nem vir", pois se encontravam no silêncio e no "traço de ouro" da poesia, situação definida pelo poeta como "convergência extasiada", conforme versos inéditos de Drummond que imortalizam a poeta amiga.

Em 16 de setembro de 1973, escrevendo à amiga a propósito de Uma via de ver as coisas, Carlos Drummond de Andrade fará referência ao poema "Cidade", vendo na matéria bruta dos primeiros versos, "Aqui se cava um túnel: / poço sem água, serpente do vazio.", , o caminho para se chegar à essencialidade da poesia de Dora, que capta os objetos para além da condição de coisas. De fato, o poema citado por Drummond alcança revelar o silêncio oculto das figuras da cidade, como túnel, poço, velhos, gente humilde, faróis, quando até mesmo ervas, capim, estrelas, lua, parecem acumpliciados com e sufocados por uma mesma atmosfera muda a que só a poesia pode dar voz. Tudo para Dora Ferreira da Silva era transcendência, e o mundo estava coberto de sinais. São sinais o que os insetos traçam nas folhas, as aranhas nas estátuas, o pássaro na janela. Esses sinais são signos para o poeta converter em símbolos, como a prosaica mangueira que abandona sua configuração natural para lançar raízes ao céu e se fazer imagem da Poesia, e o "menino sozinho" que aglutina a uma identidade literária uma infância universal simbolizada pelo Menino.

23 SILVA. Poesia reunida, p. 402.

24 Poema recolhido por Inês Ferreira da Silva Bianchi, filha de Dora Ferreira da Silva, em DVD que homenageia a mãe.

25 SILVA. Poesia reunida, p. 75. 
Dora Ferreira da Silva and Carlos Drummond de Andrade: the rite of poetry and friendship in the "Mango Tree Trilogy"

Abstract: This article aims to analyze the poems that compose the "Trilogia da Mangueira" (Mango Tree Trilogy), composition offered by the poet Dora Ferreira da Silva to her friend and correspondent, Carlos Drummond de Andrade. Their friendship lasted for nearly twenty years, although they had never met. Telephone conversations, letters and poems fueled the mutual affection between them. To honor her poet friend, Dora transforms the mango tree from Drummond's "Childhood" poem into the mythical tree with roots to air, which is scaled by a sacred boy, in a picture that eternalizes both the child Drummond and his poetry. Keywords: Dora Ferreira da Silva, Carlos Drummond de Andrade, Poetry.

$$
\text { Referências }
$$

ANDRADE, Carlos Drummond de. Poesia e prosa. Rio de Janeiro: Nova Aguilar, 1992.

BACHELARD, Gaston. A terra e os devaneios do repouso. São Paulo: Martins Fontes, 1990. BHAGAVAD GITA. São Paulo: Martin Claret, 2009.

BROSSE, Jacques. Mythologie des arbres. Paris: Éditions Payot \& Rivages, 2001.

DURAND, Gilbert. As estruturas antropológicas do imaginário. São Paulo: Martins Fontes, 2001.

ELIADE, Mircea. O sagrado e o profano: a essência das religiões. São Paulo: Martins Fontes, 2008.

GALVÃO, Donizete. Entrevista de Dora Ferreira da Silva. Jornal de Poesia. Revista Cult, maio 1999. Disponível em: <http://www.jornaldepoesia.jor.br/dgp5.html > e <http:// arte-vida-poesia.blogspot.com/2011/04/dora-ferreira-da-silva-entrevista.html>. Acesso em: 10 ago. 2011.

JUNQUEIRA, Ivan. Pensamento e emoção. In: SILVA, Dora Ferreira da. Cartografia do imaginário. São Paulo: T. A. Queiroz, 2003.

SILVA, Dora Ferreira da. Trilogia da mangueira. In: Cavalo Azul, São Paulo, João Scortecci Editora, n. 10, primavera de 1988.

SILVA, Dora Ferreira da. Poesia reunida. Rio de Janeiro: Topbooks, 1999. 